\title{
CARDIAC AUTONOMIC MODULATION RESPONSE AND FUNCTIONAL CAPACITY IN OLDER WOMEN
}

\author{
RESPOSTA DA MODULAÇÃOAUTONÔMICA CARDÍACA E CAPACIDADE FUNCIONAL EM MULHERES IDOSAS
}

TICLE ARTIGO ORIGINAL Artículo Original

\author{
RESPUESTA DE LA MODULACIÓN AUTONÓMICA CARDÍACA Y CAPACIDAD FUNCIONAL EN MUJERES MAYORES
}

\begin{abstract}
Flavio de Oliveira Pires' ${ }^{1}$ iD (Physical Therapist)

Leandro Moraes Pinto 1 (D) (Physical Education Professional) Herikson Araújo Costa² (iD) (Physical Education Professional) Janaína de Oliveira Brito-Monzani' (Physical Education Professional) Mário Noberto de Oliveira Sevilio' (ID) (Physical Education Professional) Henrique de Oliveira Castro 3 (ID) (Physical Education Professional) André Bonadias Gadelha ${ }^{4}$ (DD (Physical Education Professional) Cristiano Teixeira Mostarda' (D) (Physical Education Professional) Andressa Coelho Ferreira' (ID (Biomedical Technician) Almir Vieira Dibai-Filho' (DD (Physical Therapist) Carlos José Dias ${ }^{2}$ (DD (Physical Education Professional) Denílson Silva Martins ${ }^{1}$ (DD (Physical Education Professional)
\end{abstract}

1. Universidade Federal do Maranhão (UFMA), São Luís, MA, Brazil.

2. Universidade Federal do Maranhão (UFMA), Pinheiro, MA, Brazil.

3. Universidade Federal de Mato Grosso (UFMT), Cuiabá, MT, Brazil. 4. Colégio Militar de Brasília, Brasília, DF, Brazil.

\section{Correspondence:}

Flávio de Oliveira Pires

Av. dos Portugueses, 1966, Cidade Universitária Dom Delgado, São Luís, MA, Brazil. 65085-580. flaviooliveirapires@gmail.com

\section{ABSTRACT}

Objective: To analyze cardiac autonomic modulation response and functional capacity in physically active older women. Methods: Seventy-five older women (60-70 years) from the community were divided into the following groups: sedentary ( $n=19)$, hydro-gymnastics $(n=18)$, pilates $(n=19)$, and dance $(n=19)$. Blood pressure, body composition, heart rate variability, and functional capacity were assessed for the characterization of the groups at rest and 48 hours after the last physical exercise session. Results: The sedentary group presented higher waist-to-hip ratio, diastolic blood pressure, and resting heart rate compared to the other groups $(p<0.05)$. It was also observed that the dance group presented better functional capacity and $\mathrm{VO}_{2}$ peak scores (all $p<0.05$ ). Regarding cardiac autonomic modulation, both dance and pilates groups demonstrated better RMSSD (26.71 \pm 9.07 and $29.82 \pm 7.16$, respectively; $p<0.05)$, LF $(45.79 \pm 14.81$ and $45.95 \pm 15.16$ n.u., respectively; $p<0.05)$, and LF/HF ( $0.92 \pm 0.56$ and $0.58 \pm 0.26$, respectively; $p<0.05)$ scores. In the symbolic analysis, the dance group had a greater predominance of parasympathetic autonomic modulation than the other groups $(p<0.05)$. Conclusion: These results conclude that physically active elderly women, practicing hydro-gymnastics, pilates or dance, presented physiological benefits, such as better functional capacity and improvements in hemodynamic variables and autonomic cardiac modulation. In addition, the group that practiced dance presented greater parasympathetic modulation, as well as greater functional capacity, when compared to the other modalities. Level of evidence: l; STARD: studies of diagnostic accuracy.

Keywords: Physical exercise; Exercise movement techniques; Dancing; Functional residual capacity.

\section{RESUMO}

Objetivo: Analisar a resposta da modulação autonômica cardíaca e a capacidade funcional em idosas fisicamente ativas. Métodos: Setenta e cinco mulheres idosas (60 a 70 anos) da comunidade foram divididas nos seguintes grupos: sedentária $(n=19)$, hidroginástica $(n=18)$, pilates $(n=19)$ e dança $(n=19)$. A pressão arterial, a composição corporal, a variabilidade da frequência cardíaca e a capacidade funcional foram avaliadas para a caracterização dos grupos em repouso e 48 horas depois da última sessão de exercício físico. Resultados: O grupo sedentário apresentou maior relação cintura-quadril, pressão arterial diastólica e frequência cardíaca em repouso quando comparado aos outros grupos $(p<0,05)$. Observou-se também que o grupo da dança apresentou melhores escores de capacidade funcional e VO2pico (todos $p<0,05$ ). Com relação à modulação autonômica cardíaca, os grupos de dança e pilates demonstraram melhores escores para RMSSD (26,71 $\pm 9,07$ e 29,82 $\pm 7,16$, respectivamente; $p<0,05), \operatorname{LF}(45,79 \pm$ $14,81$ e 45,95 $\pm 15,16 \mathrm{nu}$, respectivamente; $p<0,05)$ e LF/HF $(0,92 \pm 0,56$ e 0,58 $\pm 0,26$, respectivamente; $p<0,05)$. Na análise simbólica, o grupo da dança apresentou maior predominância da modulação autonômica parassimpática do que os demais grupos $(p<0,05)$. Conclusão: Esses resultados concluem que idosas fisicamente ativas praticantes de hidroginástica, pilates ou dança, têm benefícios fisiológicos, como melhor capacidade funcional e melhora das variáveis hemodinâmicas e da modulação cardíaca autonômica. Além disso, o grupo que praticava dança teve maior modulação parassimpática e maior capacidade funcional quando comparado com outras modalidades. Nível de evidência: I; STARD: estudos de precisão diagnóstica.

Descritores: Exercício físico; Técnicas de exercício e de movimento; Dança; Capacidade residual funcional.

\section{RESUMEN}

Objetivo: Analizar la respuesta de la modulación autonómica cardiaca y la capacidad funcional en mujeres mayores físicamente activas. Métodos: Setenta y cinco mujeres mayores (60 a 70 años) de la comunidad fueron divididas en los siguientes grupos: sedentaria $(n=19)$, hidrogimnasia $(n=18)$, pilates $(n=19)$ y danza $(n=19)$. La presión arterial, la composición corporal, la variabilidad de la frecuencia cardíaca y la capacidad funcional fueron evaluadas para la caracterización de los grupos en reposo y 48 horas después de la última sesión de ejercicio físico. Resultados: El grupo sedentario presentó mayor relación cintura-cadera, presión arterial diastólica y frecuencia cardíaca en reposo cuando comparado a los otros grupos $(p<0,05)$. Se observó que el grupo de danza presentó mejores puntajes de capacidad funcional y VO2Pico (todos $p<0,05$ ). Con relación a la modulación autonómica cardíaca, los grupos de danza y pilates demostraron mejores puntajes para RMSSD $(26,71 \pm 9,07$ y 29,82 $\pm 7,16$, respectivamente; $p<0,05), \operatorname{LF}(45,79 \pm 14,81$ y 
$45,95 \pm 15,16$ nu, respectivamente; $p<0,05)$, y LF/HF $(0,92 \pm 0,56$ y $0,58 \pm 0,26$, respectivamente; $p<0,05)$. En el análisis simbólico, el grupo de danza presentó mayor predominancia de la modulación autonómica parasimpática que los demás grupos $(p<0,05)$. Conclusión: Esos resultados concluyen que las mujeres mayores físicamente activas, practicantes de hidrogimnasia, pilates o danza, tienen beneficios fisiológicos, como mejor capacidad funcional y mejora de las variables hemodinámicas y de la modulación cardíaca autonómica. Además, el grupo que practicaba danza tuvo mayor modulación parasimpática y mayor capacidad funcional cuando comparado con las otras modalidades.

Nivel de evidencia: I; STARD: estudios de precisión diagnóstica.

Descriptores: Ejercicio físico; Técnicas de ejercicio con movimientos; Baile; Capacidad residual funcional.

\section{INTRODUCTION}

Physiological aging-related declines impose difficulties for older people during lifespan, mainly regarding functional capacity (FC). ${ }^{1}$ The progressive decreasing in $\mathrm{FC}$ among older adults has been associated with several factors, such as worse socioeconomic, biological conditions and diminished health. ${ }^{2}$

In this scenario, autonomic modulation plays an important role in $\mathrm{FC}$, since it is pivotal for hormesis function. Of note, it has been postulated that women are more susceptible to uncapable function outcomes, ${ }^{3}$ since they present lower skeletal muscle mass and strength over the lifespan when compared to men. ${ }^{3}$ In this scenario, exercise programs that involve strength and moto coordination training, such as dancing, hydro-gymnastic, and pilates have been demonstrated capable for improving $\mathrm{FC}$ and act as a preventive intervention to minimize the risk of falls in the elderly population. ${ }^{4}$

Regular and guided practice of hydro-gymnastics in older people promotes some advantages in their physical capacities, such as heating of muscles and joints, which contributes to the treatment or prevention of joint impairments; improving venous return, while decreasing peripheral pressure, hydro-gymnastics also induces the relaxation of the body, and consequently reducing pain and decreasing muscle spasms. ${ }^{5}$

Dance can also contribute to the improvement and maintenance the $F C$, since it represents an expressive form of movements guided by the music. ${ }^{6}$ Through dance, practitioners can arouse positive emotions, pleasure, and socialization. ${ }^{6}$ Dance is inserted in programs of physical activities which provide social participation opportunities, stimulating the development of functional aptitudes, and especially stimulating biopsychosocial skills. ${ }^{6}$

Recently, pilates has gained popularity among aged people and has been demonstrated an alternative to maintain or improve FC of this population. Pilates comprises a system of exercises enabling to work the whole body and that corrects posture and realigns the muscles, thus present six basic principles: breathing, contraction, centralization, precision, fluidity, and control. Thus, the pilates method allows the practitioner to integrate the body and mind during exercise.?

Although physical activity has been related to better FC in different populations, including among aged people, there is a lack in the literature regarding the association among the aforementioned modalities (hydro-gymnastics, pilates and dance) and FC traits (i.e., cardiac autonomic modulation). Therefore, the aim of the present study was to analyze the response of cardiac autonomic modulation and functional capacity in elderly practitioners of different physical exercise modalities.

\section{MATERIAL AND METHODS \\ Sample collection}

The present cross-sectional study was designed to analyze the response of cardiac autonomic modulation and functional capacity in elderly practitioners of different physical exercise modalities. To reach this aim, a sample of community-dwelling women (60 to 70 years) were recruited. Exclusion criteria were as follows: participants that did not attend all the study visits, uncontrolled pathophysiological associated to age presented in the last six months, any physical disability that significantly reduces mobility or sensory functions, and elderly that performed more of one exercise modality.

A total of 75 older women were divided into the following groups: sedentary ( $n=19)$, hydro-gymnastics ( $n=18)$, pilates $(n=19)$, and dance $(n=19)$. This study followed Resolution no. 196/96 of the National Health Council of the Brazilian Ministry of Health and the study protocol was previously approved by the Institutional Review Board (87029118.4.0000.5087).

The experiment took place as follows in the active and sedentary groups. The data were collected at rest and after 48 hours of physical exercise. Blood pressure of the participants was measured once they had been in a sitting position for $5 \mathrm{~min}$. The electrocardiogram and body composition were then assessed. Thereafter, functional capacity was measured through the tests: Timed Up and Go (TUG), Timed Stands Test (TST), and Six-minute walk test (6-MWT). Lastly, the data were analyzed and tabulated using the computer program (Statistica ${ }^{\circledR} 5.0$ software). The methods used for the individual steps are described below.

\section{Clinical assessment and body composition analysis}

The anamnesis was performed through a questionnaire to identify the participants, confirm they met the inclusion criteria. Anthropometric evaluation was performed with the participant in the supine position. The weight was measured using a Balmak digital scale (in $\mathrm{kg}$ ), while the height was measured using a compact stadiometer, type EST 23 (in $\mathrm{mm}$ ). Body mass index (BMI) was calculated by dividing weight by height squared. ${ }^{8}$ Percent of body fat was measured using the adipometer in seven cutaneous folds according to Pollock and Jackson protocol. Abdominal circumference was measured using a nonelastic tape, using the greatest diameter between the last ribs and the iliac crests.

\section{Hemodynamics measure}

For blood pressure measurements, two automated blood pressure monitors were used (Omron ${ }^{\oplus}$ HEM-711 and Omron ${ }^{\oplus}$ 905). The protocol for blood pressure measurement followed the norms of the VII Brazilian Hypertension Guideline. An optimal cuff size was used according to the arm size of the participants. ${ }^{9}$

\section{Physical function assessment}

The following tests were used to assess physical function: Timed Up and Go (TUG) proposed by Podsiadlo and Richardson, The Timed Stands Test (TST) was proposed by Lira et al and The Six-minute Walk Test (6-MWT) $)^{10-12}$

Before starting Test (6-MWT), the elderly remained at rest for a period of 10 minutes for measuring blood pressure and heart rate, then the intensity of the effort was assessed using the Borg scale. Each elderly 
completed the $6 \mathrm{MW}$ test according to a standardized protocol. ${ }^{12}$ Participants were permitted to stop and rest during the test if they experienced symptoms such as lower limb pain, tachycardia, or any other symptom. To minimize bias, the elderly was not told their test results and did not observe others' results. ${ }^{13}$ All elder women were instructed to discontinue the test. After the test blood pressure, heart rate, and intensity of the effort were assessed.

The heart rate variability (HRV) was obtained using a 12-lead electrocardiogram device (MicromedWincardio 600 hz, Brasilia, DF, Brazil), and recorded using the program WinCardio 6.1.1. For this evaluation, the elderly women were instructed to remain at rest in supine position for $10 \mathrm{~min}$. The indices were evaluated using the Kubios Analysis software HRV version 2.0 (Kubios, Finland) for power spectral analyses of heart rate variability in the time and frequency domains.

The HRV measures that were evaluated in the time domain included the variables SDNN, RMSSD, pNN50, SD1, and SD2 by nonlinear analysis, in addition to total variance. In the frequency domain, the spectrum resulting from Fast Fourier Transform modeling was derived from all the data in a minimum 5-min window from the recorded signal. This includes the entire signal variance, regardless of whether its frequency components appear as specific spectral peaks or as nonpeak broa$\mathrm{dband}$ powers. The frequency bands used for the spectral analysis were low-frequency $(\mathrm{LF}, 0.04-0.15 \mathrm{~Hz})$, high-frequency $(\mathrm{HF}, 0.15-0.4 \mathrm{~Hz})$, and autonomic balance (LF/HF), a component proposed as a measure of cardiac sympatho-vagal balance.

The Shannon Entropy is obtained by quantizing of the RRi series into six levels ranging from 0 to 5, organized into patterns with 3 symbols, that means that each heartbeat corresponds to a symbol. Then, symbolic analysis was carried out by grouping the patterns with 3 symbols into four families as follows: (a) no variation (OV or OV\%: all the symbols are equal and reflects sympathetic modulation, i.e. 3,3,3); (b) one variation (1V or 1V\%: 2 consecutive symbols are equal and the remaining symbol is different, reflects sympathetic and parasympathetic modulation, i.e. 3,3,2); (c) two like variations (2LV or 2LV\%: the 3 symbols form an ascending or descending ramp, reflects sympathetic and parasympathetic modulation with vagal predominance, i.e. 1,3,5); and (d) two unlike variations (2UV or 2 UV\%: the three symbols form a peak or a valle, reflects, exclusively, vagal modulation, i.e. $3,5,3) \cdot{ }^{14}$

\section{Statistical analysis}

Data were subjected to the Kolmogorov-Smirnov normality test. For analysis of the differences between the groups, t-test and one-way ANOVA. The level of significance was established at $p<0.05$. Data are represented as mean \pm standard error of the mean. Statistica 5.0 software was used for data analysis.

\section{RESULTS}

Table 1 shows the characteristics of the study participants such as anthropometric variables, functional capacity, and hemodynamic parameters. Regarding to anthropometric variables, dance and pilates groups presented lower body weight and lower body mass index when compared to sedentary group. Also, the active groups presented lower WHRI index compared to the sedentary group. Besides, regarding to hemodynamic parameters our results showed significant results in DBP and HR in the active groups when compared to the sedentary group. In addition, SBP did not presented differences between groups.

The functional tests (TUG, TST and 6-WMT) is presented in the Table 1 and Figure 1. Our results showed a lower execution time in the active groups for TUG, highlighting a better result in the dance group compared to the hydro-gymnastics and pilates groups. In TST, it was observed
Table 1. Characteristics of the sample.

\begin{tabular}{c|c|c|c|c|}
\hline \multicolumn{5}{c}{ Groups } \\
\hline Variables & $\begin{array}{c}\text { SG } \\
(n=19)\end{array}$ & $\begin{array}{c}\text { DG } \\
(n=19)\end{array}$ & $\begin{array}{c}\text { HG } \\
(n=18)\end{array}$ & $\begin{array}{c}\text { PG } \\
(n=19)\end{array}$ \\
\hline
\end{tabular}

Anthropometric Parameters

\begin{tabular}{c|c|c|c|c}
\hline Age (years) & $64.71 \pm 2.66$ & $66.05 \pm 2.34$ & $64.44 \pm 3.63$ & $66.26 \pm 4.88$ \\
\hline Weight $(\mathrm{kg})$ & $65.34 \pm 5.76$ & $56.20 \pm 7.41^{*}$ & $60.42 \pm 8.03$ & $58.38 \pm 10.17^{*}$ \\
\hline Height $(\mathrm{m})$ & $1.51 \pm 0.03$ & $1.53 \pm 0.04$ & $1.51 \pm 0.00$ & $1.52 \pm 0.04$ \\
\hline BMI $\left(\mathrm{kg} / \mathrm{m}^{2}\right)$ & $28.59 \pm 2.25$ & $24.01 \pm 2.97^{*}$ & $26.50 \pm 3.02$ & $25.27 \pm 3.93^{*}$ \\
\hline WHRI $(\mathrm{cm})$ & $0.90 \pm 0.03$ & $0.82 \pm 0.05^{*}$ & $0.84 \pm 0.01^{*}$ & $0.83 \pm 0.00^{*}$ \\
\hline
\end{tabular}

Hemodynamic Parameters

\begin{tabular}{l|l|l|l|l} 
SBP $(\mathrm{mmHg})$ & $135.28 \pm 13.32$ & $128.63 \pm 15.27$ & $124.05+15.95$ & $125.78 \pm 19.63$ \\
\hline
\end{tabular}

\begin{tabular}{l|c|c|c|c}
$\mathrm{DBP}(\mathrm{mmHg})$ & $83.57 \pm 3.98$ & $77.62 \pm 2.89^{*}$ & $76.50 \pm 5.76^{*}$ & $73.81 \pm 5.67^{*}$
\end{tabular}

\begin{tabular}{l|l|l|l|l} 
Heart Rate & & & $76.50 \pm 5.76^{*}$ & $73.81 \pm 5.67^{*}$ \\
\hline
\end{tabular}
\begin{tabular}{l|l}
$76.28 \pm 4.50$ & $67.34 \pm 4.56^{*}$
\end{tabular}

$68.71 \pm 7.01^{*}$ $58.32 \pm 11.04^{* * \$}$ Functional Capacity

\begin{tabular}{c|c|c|c|c}
\hline TUG $(\mathrm{s})$ & $11.33 \pm 2.19$ & $7.26 \pm 0.99^{* \$}$ & $8.94 \pm 1.51^{*}$ & $8.26 \pm 0.99^{*}$ \\
\hline TST $(\mathrm{reps})$ & $10.90 \pm 1.78$ & $13.26 \pm 1.48^{*}$ & $11.72 \pm 2.16$ & $12.68 \pm 1.94^{*}$ \\
\hline 6-MWT $(\mathrm{m})$ & $506.30 \pm 41.99$ & $606.36 \pm 48.21^{*+}$ & $599.77 \pm 59.05^{*+}$ & $535.92 \pm 54.95$ \\
\hline $\begin{array}{c}\mathrm{VO}_{2 \text { Peak }} \\
(\mathrm{ml} / \mathrm{kg} / \mathrm{min})\end{array}$ & $18.18 \pm 1.58$ & $21.47 \pm 1.61^{*+}$ & $20.99 \pm 1.77^{*+}$ & $19.02 \pm 1.43$ \\
\hline
\end{tabular}

$\mathrm{SG}=$ sedentary group; $\mathrm{DG}=$ dance group; $\mathrm{HG}=$ hydro-gymnastics group; $\mathrm{PG}=$ pilates group; $\mathrm{BMI}=$ Body Mas Index; WHRI = Waist-Hip Ratio Index; SBP = Systolic Blood Pressure; DBP = Diastolic Blood Pressure; TUG = Timed Up and Go; TST = Timed-Stands Test; 6-MWT = 6-MinutesWalk Test. Data are presented as mean \pm standard deviation, based on one-way variance test (ANOVA One Way) with Post Hoc Tukey test; * $p<0.05$ vs. Sedentary; $p<0.05$ vs. Hydro-gymnastic; $\uparrow<<0.05$ vs. Pilates.

a higher number of repetitions in the dance and pilates groups when compared to sedentary and hydro-gymnastics groups.

Significant results were observed in the dance and hydro-gymnastics groups in the 6-WMT and VO2 Pico (Table 1) compared to pilates and sedentary groups.

Table 2 shows the results of the autonomic variables in the time and frequency domains, as well as symbolic analysis. Our founds showed that the pilates group presented a higher RR interval compared to other groups. Evidencing, better results in the pilates group compared to the other groups. Besides, the active groups presented a lower heart rate when compared to the sedentary group. Dance and pilates groups presented higher RMSSD index compared to the sedentary group, highlighting better results in the pilates group. Regarding to general index (SDNN), the dance group presented higher values when compared to other groups.

In the frequency domain analysis, the LF measure (in absolute $\left(\mathrm{ms}^{2}\right.$ ) and normalized (n.u) values) were lower in the dance and pilates groups when compared to the sedentary group, presenting still a lower LF (ms) in relation to hydro gymnastics group. In additon, HF (n.u) measure, representative of the parasympathetic modulation, presented higher values in the dance and pilates groups compared to the sedentary group, showing also a better sympatho-vagal balance (LF/HF) when compared to the sedentary and hydro gymnastics groups.

In the symbolic analysis, the 0V\% was lower in the dance group compared to the sedentary and hydro gymnastics groups, while the 2LV\%, washig her in the dance when compared to the other groups. The 1V\% and 2 UV\% indices did not present significant differences between groups.

\section{DISCUSSION}

This study aimed to analyze the response of cardiac autonomic modulation and functional capacity in elderly practitioners of different physical exercise modalities. The findings of this study demonstrate that the dance when compared to other modalities presented significant differences in anthropometric, functional capacity and cardiac autonomic modulation variables. 

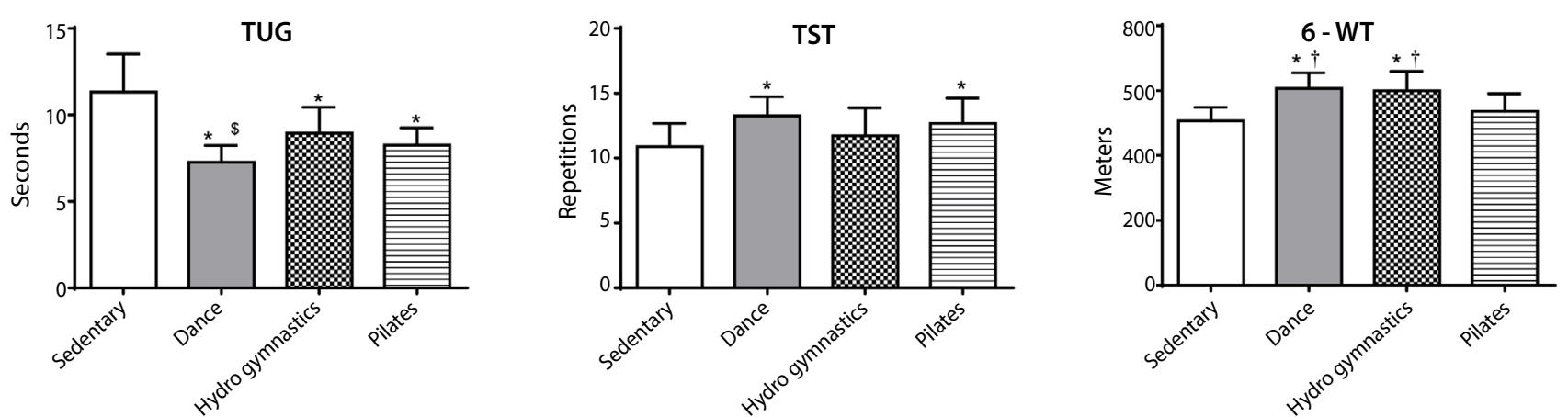

TUG = Timed Up and Go; TST = Timed-Stands Test; 6-MWT = Six-minute Walk Test. Data are presented as mean \pm standard deviation, based on one-way variance test (ANOVA One Way) with Post Hoc Tukey Test; ${ }^{2} \mathrm{p}<0.05$ vs. Sedentary; $\$ p<0.05$ vs. Hydrogymnastics; $\uparrow p<0.05$ vs. Pilates.

Figure 1. Statistical results of the functional capacity tests.

Table 2. Cardiac autonomic modulation of the sample.

\begin{tabular}{l|c|c|c|c}
\hline \multicolumn{5}{c}{ Groups } \\
\hline Variables & $\begin{array}{c}\text { SG } \\
(n=19)\end{array}$ & $\begin{array}{c}\text { DG } \\
(n=19)\end{array}$ & $\begin{array}{c}\text { HG } \\
(n=18)\end{array}$ & $\begin{array}{c}\text { PG } \\
(n=19)\end{array}$ \\
\hline \multicolumn{5}{c}{ Autonomic Indices } \\
\hline \multicolumn{5}{c}{ Time Domain }
\end{tabular}

\begin{tabular}{c|c|c|c|c}
\hline RR (ms) & $881,71 \pm 86,96$ & $931,41 \pm 125,18$ & $905,06 \pm 116,40$ & $1076,41 \pm 128,95^{* * \$}$ \\
\hline RMSSD (ms) & $20,24 \pm 4,5$ & $26,71 \pm 9,07^{*}$ & $21,71 \pm 8,19$ & $29,82 \pm 7,16^{* 5}$ \\
\hline SDNN (ms) & $24,84 \pm 10,08$ & $38,23 \pm 19,49^{* 5}$ & $25,64 \pm 11,83$ & $35,00 \pm 14,29$ \\
\hline \multicolumn{5}{c}{ Frequency Domain } \\
\hline LF (ms $\left.{ }^{2}\right)$ & $274,47 \pm 83,70$ & $143,33 \pm 77,28^{* 5}$ & $253,10 \pm 112,11$ & $91,64 \pm 32,51^{* 5}$ \\
\hline LF (nu) & $63,40 \pm 19,29$ & $45,79 \pm 14,81^{*}$ & $49,00 \pm 20,42$ & $45,95 \pm 15,16^{*}$ \\
\hline HF (ms $\left.{ }^{2}\right)$ & $124,34 \pm 54,00$ & $155,32 \pm 90,47$ & $150,28 \pm 88,40$ & $157,68 \pm 94,72$ \\
\hline HF (nu) & $36,59 \pm 19,29$ & $54,21 \pm 14,81^{*}$ & $51,00 \pm 20,42$ & $54,04 \pm 15,16^{*}$ \\
\hline LF/HF & $2,20 \pm 0,89$ & $0,92 \pm 0,56^{* 5}$ & $1,68 \pm 1,16$ & $0,58 \pm 0,26^{* 5}$ \\
\hline \multicolumn{5}{c}{ Symbolic Analysis } \\
\hline OV (\%) & $31,31 \pm 7,26$ & $17,73 \pm 4,82^{* \$}$ & $34,19 \pm 15,08$ & $25,43 \pm 11,55$ \\
\hline IV (\%) & $43,41 \pm 8,87$ & $47,58 \pm 9,71$ & $44,76 \pm 5,91$ & $47,34 \pm 7,12$ \\
\hline 2LV (\%) & $4,07 \pm 2,00$ & $11,18 \pm 6,01^{*}$ & $8,12 \pm 7,99$ & $8,70 \pm 5,79$ \\
\hline 2UV (\%) & $20,82 \pm 5,82$ & $23,60 \pm 11,60$ & $21,29 \pm 9,04$ & $22,84 \pm 11,22$ \\
\hline
\end{tabular}

$\mathrm{SG}=$ sedentary group; $\mathrm{DG}=$ dance group; $\mathrm{HG}=$ hydrogymnastics group; $\mathrm{PG}=$ pilates group; $\mathrm{RR}: \mathrm{RR}$-interval variability; RMSSD: square root of squared mean of the differences between adjacent normal R-R intervals, expressed in milliseconds: SDNN: standard deviation of the mean of qualified NN-interval LF: low frequency component; HF: high frequency component: LF/HF: ratio between low and high frequency components; $O V(\%)$ : all the symbols are fuval $1 \mathrm{~V}(\%)$ : 2 consecutive symbols are equal and the remaining symbol is different; $2 \mathrm{LV}(\%)$ : the 3 symbols

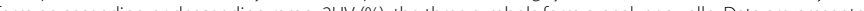
form an ascending or descending ramp; $20 \mathrm{~V}(\%)$. the three symbols fom a peak or avale, Data are presente as mean \pm standard deviation, based on One-way variance test (ANOVA) with Post Hoc Tukey Test; * $p<0.05$ vs. Sedentary; $\# p<0.05$ vs. Dance; $\$ p<0.05$ vs. Hydrogymnastics.

These differences may be associated with the different muscle groups required in the dance, increasing the capacity of the muscular and cardiovascular systems, as showed in study performed by Belardinelli et al. ${ }^{15}$ In this study, the authors demonstrate that the regular practice of this modality of physical exercise is associated with beneficial changes in balance, strength, flexibility, and cardiovascular capacity. ${ }^{15}$

As for the functional capacity, dance and pilates groups present better results of TUG and TST tests when compared to hydro-gymnastics group. Possibly due to greater demand of the muscular system in relation the cardiovascular aerobic system. ${ }^{16-19}$ Thus, the activities of these groups induce a greater demand for muscular activity in relation to hydro-gymnastics, once this modalities reduces gravitational forces and mechanical stress of the musculoskeletal system. ${ }^{20}$

In contrast, the 6-minute Walk Test is significant I y related to a higher demand of the cardiovascular system in according to the results of the present study. Dance and hydro-gymnastics obtained the better results when compared to the other groups, we suggest that these results are related to a higher demand of the cardiovascular system in these groups. ${ }^{20-22}$

As for the dance group, our founds for TUG (mean time: 7.26 seconds) presented a lower execution speed mean when compared to a study of a similar population. ${ }^{23}$ In this study, the authors obtained a mean time of 2.26, in this same test, when evaluating Traditional Thai Dance. We suggest that these differences occurred because our study is a cross-sectional study where physical training parameters were not controlled, while the second study performed a longitudinal follow, in which the elderly women were evaluated for 12 weeks.

In this study, the functional tests for pilates group showed execution speed mean of 8.26 seconds in the TUG, similar value presented in a previous study, ${ }^{24}$ which presented an execution speed mean of 8.1 seconds. Regarding studies performed with elderly, we did not find results related to the TST and 6-MWT for this modality.

As for the hydro-gymnastics group, our results for TUG showed an execution speed mean of 8.94 seconds, corroborating with study performed by Moreira et al. ${ }^{25}$ In the same study, the TST was performed, presenting a mean of 12.5 and 12.9 repetitions for the groups evaluated, however in our study we obtained a mean of 11.72 repetitions.

In the study performed by Batista et al.. ${ }^{26}$ which aimed to compare hemodynamic responses after 4 acute sessions of Mat Pilates, aerobic exercises and resistance exercises, it was possible to identify a reduction in systolic blood pressure, diastolic blood pressure and mean blood pressure after aerobic and resistance exercise sessions, but not in the pilates session, which differs with our findings, once the pilates presented lower diastolic blood pressure when compared to the sedentary group. We also emphasize that, in our study, pilates group presented a lower heart rate than the other groups. ${ }^{26}$

In this study, the autonomic responses in the dance group showed similar results to a previous study as demonstrated by the normalized HF index that is related to parasympathetic modulation. ${ }^{27}$ In our results, we observed better values of LF (in ms $^{2}$ and n.u), HF (n.u) and sympatho-vagal balance (LF / HF), which corroborates with a study by Sampaio et al., ${ }^{28}$ who performed a dance protocol for 6 weeks with elderly. According to our results we suggest that, the significant changes observed in frequency domain indices reflect, directly, on differences observed in time domain (RMSSD and SDNN indices) and symbolic analysis (OV (\%) and 2LV (\%)).

Thus, it was possible to verify that the elderly women practitioners of regular physical activities like dance, pilates and hydro-gymnastics present physiological benefits such as better functional capacity, hemodynamic variables and autonomic modulation, demonstrating still that the dance presented better results than the other modalities studied (pilates and hydro-gymnastics). In this sense, the dance demonstrates several health benefits, once this exercise present wide spread popular appeal and can be performed without the use of equipment and specific environments like used by the other modalities. ${ }^{25,29,30}$

It is important to note that our study had some caveats, one of them being the follow-up period and with it, some important variables in the physical training could not be controlled. 
Therefore, this study showed that exercise plays an important role in the autonomic modulation and dance, pilates, and hydro-gymnastics present physiological benefits such as better HR, hemodynamic outcomes, and autonomic modulation in older women. It was also demonstrated that dance presented a greater predominance of the parasympathetic modulation as well as greater functional capacity in relation to the other modalities.

\section{ACKNOWLEDGEMENTS}

Fundação de Amparo à Pesquisa e Desenvolvimento Científico e Tecnológico do Estado do Maranhão (FAPEMA).

All authors declare no potential conflict of interest related to this article

AUTHORS' CONTRIBUTIONS: Each author made significant individual contributions to this manuscript. FOP: intellectual concept and preparation of the entire research project, data collection, text writing, data analysis, text review and study planning. LMP: data collection, text writing, data analysis, text review and study planning. HAC: data collection, text writing and text review. JPBM: data collection, text writing and text review. MNOS: data collection, text writing and text review. AVDF: text review, data analysis, and intellectual concept and preparation of the entire research project. CJD: text review, data analysis, intellectual concept and preparation of the entire research project. DSM: text review, data analysis, intellectual concept and preparation of the entire research project. HOC: text review, data analysis, intellectual concept, preparation of the entire research project and study planning. ABG: text review, data analysis, intellectual concept and preparation of the entire research project. ACF: text review, data analysis, intellectual concept and preparation of the entire research project. CTM: intellectual concept, preparation of the entire research project, data collection, text writing, data analysis, text review and study planning.

\section{REFERENCES}

1. Posser SC, Leguisamo CP, Oliveira B, Oliveira LZ, Bavaresco SS. Neuropatia diabética: um relato de caso. EFDeportes.com. 2012;17:175.

2. Nogueira SL, Ribeiro RCL, Rosado LEFPL, Franceschini SCC, Ribeiro AQ, Pereira ET. Fatores determinantes da capacidade funcional em idosos longevos. Rev Bras Fisioter. 2010;14(4):322-9.

3. Newman AB, Kupelian V, Visser M, Simonsick E, Goodpaster B, Nevitt M, et al. Sarcopenia: alternative definitions and associations with lower extremity function. J Am Geriatr Soc. 2003;51(11):1602-9.

4. Ruiz-Montero PJ, Castillo-Rodriguez A, Mikalacki M, Nebojsa C, Korovljev D. 24-weeks Pilates-aerobic and educative training to improve body fat mass in elderly Serbian women. Clin Interv Aging. 2014;9:243-8.

5. Vagetti GC, Oliveira V, Silva MP, Pacífico AB, Costa TRA, Campos W. Associação do índice de massa corporal com a aptidão funcional de idosas participantes de um programa de atividade física. Rev Bras Geriatr Gerontol. 2017;20(2):214-24.

6. Witter C, Buriti MA, Silva GB, Nogueira RS, Gama EF. Envelhecimento e dança: análise da produção científica na Biblioteca Virtual de Saúde. Rev Bras Geriatr Gerontol. 2013;16(1):191-9.

7. Kloubec J. Pilates: how does it work and who needs it? Muscles Ligaments Tendons J. 2011;1 (2):61-6

8. Charro MR, Bacurau, RF. Manual de avaliação física. São Paulo: Phorte, 2010.

9. Beevers G, Lip GY, O'Brien E. ABC of hypertension: Blood pressure measurement: Part II—Conventional sphygmomanometry: technique of auscultatory blood pressure measurement. BMJ. 2001;322(7293):1043-7.

10. Podsiadlo D, Richardson S. The timed "Up \& Go": a test of basic functional mobility for frail elderly persons. J Am Geriatr Soc. 1991;39(2):142-8.

11. Lira VA, Silva EB, Araujo CGS. As ações de sentar e levantar do solo são prejudicadas por excesso de peso. Rev Bras Med Esporte. 2000;6(6):241-8.

12. Langoni CS, Borsatto AC, Valmorbida LA, Resende TL. Teste de caminhada de seis minutos em idosos de uma instituição de longa permanência: valores, aplicabilidade e correlações. Revista Brasileira de Ciências do Envelhecimento Humano. 2013;10(3):285-95.

13. Britto RR, Sousa LAP. Teste de caminhada de seis minutos uma normatização brasileira. Fisioter Mov. 2006;19(4):49-54

14. Guzzetti S, Borroni E, Garbelli PE, Ceriani E, Della Bella P, Montano N, et al. Symbolic dynamics of heart rate variability: a probe to investigate cardiac autonomic modulation. Circulation. 2005;112(4):465-70.

15. Belardinelli R, Lacalaprice F, Ventrella C, Volpe L, Faccenda E. Waltz-Dancing in Patients With Chronic Heart Failure: A New Form of Exercise Training. Circ Heart Fail. 2008;1 (2):107-14.

16. Nicolini-Panisson RD'A, Donadio MVF. Teste Timed “Up \& Go” em crianças e adolescentes. Rev Paul Pediatr. 2013;31(3):377-83.

17. Luc-Harkey BA, Safran-Norton CE, Mandl LA, Katz JN, Losina E. Associations among knee muscle strength, structural damage, and pain and mobility in individuals with osteoarthritis and symptomatic meniscal tear. BMC Musculoskeletal Disorders. 2018;19(258).

18. Pettersson H, Boström C, Bringby F, Walle-Hansen R, Jacobsson L, Svenungsson E, et al. Muscle endurance, strength, and active range of motion in patients with different subphenotypes in systemic sclerosis: a cross-sectional cohort study. Scand J Rheumatol. 2019;48(2):141-8.

19. Lee FI, Lee TD, So WK. Effects of a tailor-made exercise program on exercise adherence and health outcomes in patients with knee osteoarthritis: a mixed-methods pilot study. Clin Interv Aging. 2016;11:1391-402.

20. Souto AL, Lima LM, Castro EA, Veras RP, Segheto W, Zanatta TC, et al. Blood pressure in hypertensive women after aerobics and hydrogymnastics sessions. Nutr Hosp. 2015;32(2):823-8.

21. Gusi N, Tomas-Carus P, Hakkinen A, Hakkinen K, Ortega-Alonso A. Exercise in waist-high warm water decreases pain and improves health-related quality of life and strength in the lower extremities in women with fibromyalgia. Arthritis Rheum. 2006;55(1):66-73.

22. Wang TJ, Belza B, Thompson FE, Whitney JD, Bennett K. Effects of aquatic exercise on flexibility, strength and aerobic fitness in adults with osteoarthritis of the hip or knee. J Adv Nurs. 2007;57(2):141-52.

23. Noopud P, Suputtitada A, Khongprasert S, Kanungsukkasem V. Effects of Thai traditional dance on balance performance in daily life among older women. Aging Clin Exp Res. 2019;31(7):961-7.

24. 24. Mesquita LSA, Carvalho FT, Freire LSA, Neto OP, Zângaro RA. Effects of two exercise protocols on postural balance of elderly women: a randomized controlled trial. BMC Geriatr. 2015;15:61.

25. Moreira OC, Lopes GS, Matos DG, Mazini-Filho ML, Aidar FJ, Silva SF, et al. Impact of two hydrogymnastics class methodologies on the functional capacity and flexibility of elderly women. J Sports Med Phys Fitness. 2019;59(1):126-31.

26. Batista JP, Mariano IM, Souza TCF, Costa JG, Giolo JS, Cheik NC, et al. The Acute Effects of Mat Pilates on Hemodynamic and Salivary Nitrate Responses After Exercise in Postmenopausal Women. J Aging Phys Act. 2019;27(3):371-7.

27. Bernardi NF, Bellemare-Pepin A, Peretz I. Enhancement of pleasure during spontaneous dance. Front Hum Neurosci. 2017;11:572.

28. Sampaio LM, Subramaniam S, Arena R, Bhatt T. Does virtual reality-based kinect dance training paradigm improve autonomic nervous system modulation in individuals with chronic stroke? J Vasc Interv Neurol. 2016;9(2):21-9.

29. Judge JO. Balance training to maintain mobility and prevent disability. Am J Prev Med. 2003;25(3 Suppl 2):150-6.

30. Eliks M, Zgorzalewicz-Stachowiak M, Zenczak-Praga K. Application of Pilates-based exercises in the treatment of chronic non-specific low back pain: state of the art. Postgrad Med J. 2019;95(1119):41-5 